\title{
Responses of boreal ground beetles (Coleoptera, (arabidae) to different logging regimes during ten years of secondary succession
}

\author{
Matti J Koivula $\ddagger$ \\ ‡ University of Eastern Finland, Joensuu, Finland
}

Corresponding author: Matti J Koivula (mjkoivula@gmail.com)

Received: 19 Jul 2019 | Published: 19 Jul 2019

Citation: Koivula MJ (2019) Responses of boreal ground beetles (Coleoptera, Carabidae) to different logging regimes during ten years of secondary succession. ARPHA Conference Abstracts 2: e38377.

https://doi.org/10.3897/aca.2.e38377

\section{Abstract}

Many biological responses may develop over long periods of time, and annual community variation should therefore be controlled in ecological research. We sampled carabid beetles over ten years in Norway spruce dominated forests in Southern Finland, harvested using replicated logging treatments of different intensities. We collected carabids in 1995 (prior to logging) and during four post-harvest seasons, 1996-98 and in 2006. The treatments were clear-cutting (no retained trees), modified clear-cutting (retention of three groups of 20-30 trees within one-hectare core) and gap cutting (three 0.16-ha openings within a one-hectare core), and control (mature unharvested forest).

1. Carabids showed remarkable annual and regional variation at assemblage, ecological-group and species levels, such that was independent of treatments.

2. The total species richness, and that of open-habitat carabids, were higher in cleared sites of all treatments than in control stands in 1997-1998 but not in 2006, suggesting that the logging response was ephemeral by many species.

3. The abundances of forest and generalist carabids were little affected by logging. Open-habitat carabids were more abundant in clear-cuts and modified clear-cuts than in gap cuts, which was still detectable in 2006, suggesting a long-term effect. 
4. Open-habitat carabids were less abundant in retention sites of modified clear-cuts and gap cuts than in cleared sites, suggesting that retention attenuates assemblage change.

5. Carabid assemblages of logged stands did not differ from control stands in 1996 but they did in 1997-1998, suggesting a one-year delay in logging response.

In 2006, logged and control stands hosted relatively similar assemblages which, together with the above results, suggests a partial faunal recovery. We conclude that even modest retention provides long-term support for forest carabids, but also that their full assemblage recovery takes longer than 10 years.

\section{Keywords}

Clear cutting, Gap cutting, Retention, Selection cutting, Thinning

\section{Presenting author}

Matti Koivula

\section{Presented at}

19thECM oral communication 